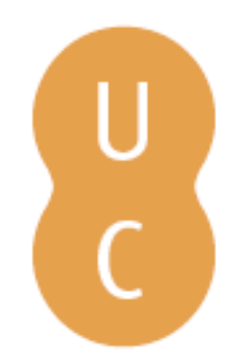

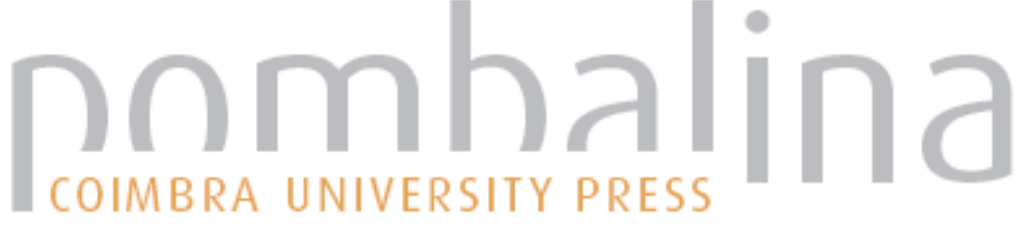

\section{Identificação genética de desconhecidos}

\author{
Autor(es): $\quad$ Espinheira, Rosa Maria
}

Publicado por: Imprensa da Universidade de Coimbra

URL

persistente: URI:http://hdl.handle.net/10316.2/38504

DOI: $\quad$ DOI:http://dx.doi.org/10.14195/978-989-26-0957-7_3

Accessed : $\quad$ 26-Apr-2023 15:25:09

A navegação consulta e descarregamento dos títulos inseridos nas Bibliotecas Digitais UC Digitalis, UC Pombalina e UC Impactum, pressupõem a aceitação plena e sem reservas dos Termos e Condições de Uso destas Bibliotecas Digitais, disponíveis em https://digitalis.uc.pt/pt-pt/termos.

Conforme exposto nos referidos Termos e Condições de Uso, o descarregamento de títulos de acesso restrito requer uma licença válida de autorização devendo o utilizador aceder ao(s) documento(s) a partir de um endereço de IP da instituição detentora da supramencionada licença.

Ao utilizador é apenas permitido o descarregamento para uso pessoal, pelo que o emprego do(s) título(s) descarregado(s) para outro fim, designadamente comercial, carece de autorização do respetivo autor ou editor da obra.

Na medida em que todas as obras da UC Digitalis se encontram protegidas pelo Código do Direito de Autor e Direitos Conexos e demais legislação aplicável, toda a cópia, parcial ou total, deste documento, nos casos em que é legalmente admitida, deverá conter ou fazer-se acompanhar por este aviso. 


\section{PRINCÍPIOS}

\section{DE GENÉTICA}

\section{FORENSE}

FRANCISCO CORTE-REAL DUARTE NUNO VIEIRA

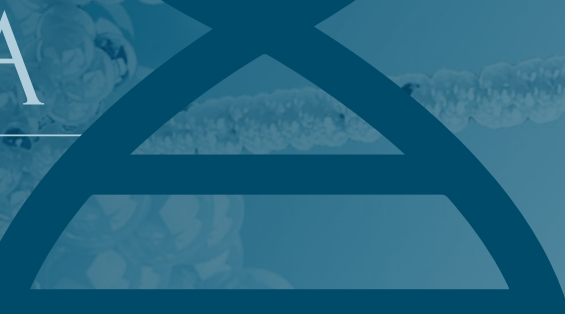

c)
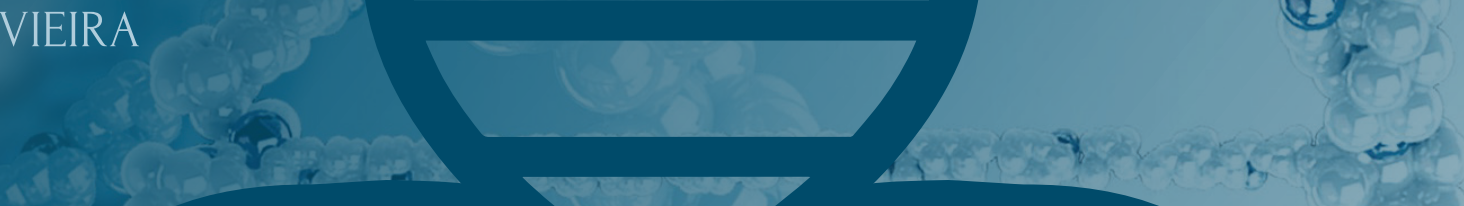

(4)

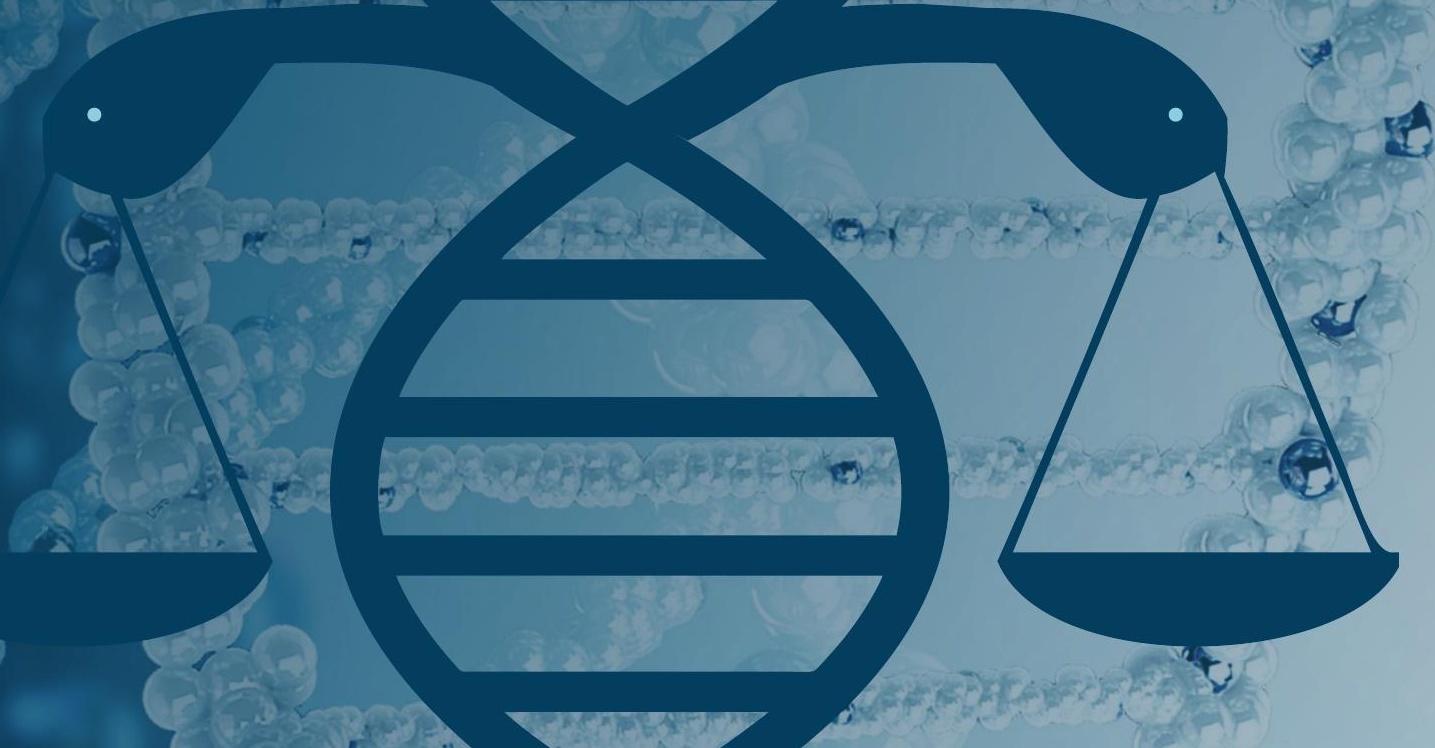

min $2(5)$

Exar. 
Capítulo 3

IDENTIFICAÇÃO GENÉTICA DE DESCONHECIDOS

\section{Rosa Maria Espinheira}

Instituto Nacional de Medicina Legal e Ciências Forenses, I.P.

CENCIFOR - Centro de Ciências Forenses

DOI | HTTP://DX.DOI.ORG/10.14195/978-989-26-0957-7_3 


\section{RESUMO}

A identificação genética de desconhecidos não figura, em termos quantitativos, no topo das perícias realizadas por um serviço de genética forense em Portugal. Se por um lado a identificação genética de um indivíduo desconhecido só tem lugar quando nenhum outro método científico de identificação individual permitiu uma identificação positiva, por outro lado, a mesma, em grande escala, só tem lugar nos casos de desastres de massa com consideráveis números de vítimas, os quais, não tem lugar com registo na história contemporânea de Portugal. Não obstante a reduzida casuística dos casos de identificação genética de desconhecidos em Portugal, não podemos deixar de atribuir realce ao importante papel, quer em termos sociais quer humanitários, desta ferramenta que a genética forense disponibiliza.

Neste capítulo abordamos a identificação genética de desconhecidos fazendo uma retrospectiva histórica de casos com especial impacto ou interesse, passando por aspectos como o âmbito de aplicação da identificação genética, bem como por aspectos mais técnicos como o tipo de amostras estudadas, os procedimentos laboratoriais utilizados e os principais obstáculos ao sucesso da perícia de identificação genética de desconhecidos. O modesto e despretensioso contributo que aqui deixamos não se apresenta como um referencial técnico ou científico sobre esta matéria, mas sim como um documento simultaneamente útil e acessível ao entendimento de operadores tão diversos como juristas ou magistrados, médicos e demais especialistas das áreas médicas e biomédicas, bem como a estudantes e estudiosos de nível pré e pós-graduado desta área em que todos confluem com o objectivo último de, em primeira instância, servir a justiça e, em ultima instância, servir o bem e a causa pública.

\section{PALAVRAS-CHAVE}

Identificação genética; desconhecidos; desastre de massa.

\section{SUMMARY}

Genetic identification of unknown missing persons is not on the top of exams performed by a forensic genetics service in Portugal. If on one hand the genetic identification of an unknown individual only takes place when no other scientific individual identification method allowed a positive identification, on the other hand, it only takes place on a large scale in case of mass disasters with considerable number of victims, which has no place in Portuguese contemporary history. Despite the small sample size of genetic identification cases of unknown persons in Portugal, we cannot fail to give prominence to the role, either in social or humanitarian terms, of this tool provided by forensic genetics.

In this chapter we discuss the genetic identification of unknown persons making a historical retrospective of cases with special impact or interest, through aspects such as the scope of genetic identification, as well as more technical aspects such as the type of analyzed samples, the laboratory procedures and the main obstacles to the success of the genetic identification exams of unknown persons.

The modest and unpretentious contribution we leave here is not presented as a technical or scientific reference on this matter, but as an useful and accessible understanding to the operators as diverse as lawyers and judges, doctors and other experts in medical and biomedical areas, as well as students and scholars of pre and post-graduate level of this area where all converge with the ultimate aim of, in the first instance, serve the justice, and ultimately, serve the good and the public cause.

\section{KEYWORDS}

Genetic identification; unknown persons; mass disaster 


\section{NOTA INTRODUTÓRIA}

A Assembleia Geral da Organização das Nações Unidas (ONU) proclamou, a 10 de Dezembro de 1948, a Declaração Universal dos Direitos do Homem. Esta declaração prevê, no âmbito dos direitos fundamentais do Homem, o direito, por todos os indivíduos, em todos os lugares, ao reconhecimento da sua personalidade jurídica, o que, de entre múltiplas e diversas implicações significa, também, que todo o Homem tem direito, em todos os lugares, e, em todas as situações, ao reconhecimento da sua identidade, e, portanto à sua identificação individual.

Contrariamente ao que se passa com a maior parte dos indivíduos vivos ou cadáveres humanos frescos, a identificação visual não tem aplicação ou utilidade nos casos de cadáveres em avançados estados de decomposição, maioritariamente cadáveres esqueletizados, em remanescentes humanos, em cadáveres recentes que apresentem mutilações, e em particular mutilações faciais, e, nem mesmo, em indivíduos vivos indocumentados que não tenham, ou afirmem não ter, memória da sua identidade. Nestes casos, de acordo com orientações e consenso internacionais, a identificação individual médico-legal é realizada, sempre que possível, recorrendo à lofoscopia ou à informação médico-dentária. Quando nenhum destes métodos permitiu a identificação individual a genética forense é chamada a intervir.

Sendo, qualquer um dos métodos de identificação individual, métodos de natureza comparativa, a lofoscopia, relativamente à genética forense, tem, em princípio e na maior parte dos casos, a vantagem de ter quase sempre disponíveis dados para comparação em registos oficiais.
É muito reduzido o número de situações em que um indivíduo não tem a sua impressão digital registada em arquivos. Já no que concerne a registos médico-dentários existem em número muito reduzido se comparados com os registos lofoscópicos oficiais.

Já acima referimos que todos os métodos de identificação individual humana são métodos comparativos, e, por este facto e porque é indiscutível que quanto menor e mais específico for o grupo a que pertence o indivíduo ou resto humano a identificar, maior será a probabilidade de alcançarmos uma identificação individual positiva. Assim, o contributo prévio da antropologia forense, na orientação da investigação da identidade, é de valor inestimável.

A antropologia forense tenta estimar o sexo do cadáver, uma idade aproximada, a estatura, a afinidade populacional, o tempo decorrido post mortem, quando aplicável, e, ainda, eventualmente, aponta algumas causas e circunstâncias da morte, com vista a restringir o leque de supostos indivíduos. Com este trabalho prévio o sucesso da intervenção da lofoscopia, da medicina dentária ou mesmo da genética forense é, certamente, muito maior e mais provável (Amorim et al., 2011a).

Os métodos de genética forense, sendo mais laboriosos e incomparavelmente mais dispendiosos, implicam, à semelhança de qualquer método de identificação individual, a existência de dados anteriores para comparação. A identificação genética individual implica a existência de uma amostra de referência do suposto indivíduo, previamente colhida e devidamente identificada, ou, alternativamente, implica a existência de ascendentes, descendentes ou outros indivíduos com parentesco 
biológico com o suposto indivíduo, sendo, num número considerável de casos, a única forma de alcançar a identificação individual positiva.

A identificação genética de um indivíduo é realizada pela determinação do seu perfil genético individual, o qual é obtido pela determinação da combinação das características genéticas que este indivíduo apresenta num determinado conjunto de marcadores estudados no seu genoma. Actualmente, de acordo com as recomendações do European DNA Profiling Group (EDNAP), os marcadores genéticos de eleição para a determinação de um perfil genético individual são loci de regiões microsatélite do ADN, habitualmente designados por Short Tandem Repeats (STR). O número e os loci utilizados para a determinação de um perfil genético individual apresentam alguma variação a nível internacional, sendo definidos localmente pelas autoridades políticas e judiciárias territorialmente competentes.

\section{RETROSPECTIVA HISTÓRICA DE CASOS DE IDENTIFICAÇÃO GENÉTICA DE DESCONHECIDOS, COM ESPECIAL IMPACTO OU INTERESSE}

A Genética Forense, no âmbito da identificação de desconhecidos, tem assumido um papel relevante em situações de grande impacto social, humanitário e histórico. As metodologias utilizadas na rotina dos laboratórios forenses para estudo dos genomas nuclear e mitocondrial, tem contribuído para o esclarecimento de acontecimentos históricos, permitindo a identificação de desaparecidos em sequência de conflitos políticos, guerras, actos terroristas ou desastres de massas, como catástrofes naturais, de entre outros.

Pelo interesse histórico de que se reveste, começamos por fazer referência ao caso da identificação do último imperador da Rússia - Czar Nicolau II (Nikolái Alieksándrovich Románov), da sua esposa - Czarina Alexandra Feodorovna de Hesse (Vitória Alice Helena Luísa Beatriz de Hesse), de três dos seus cinco filhos, do médico e três criados da família imperial, todos assassinados pelos bolcheviques, em Ekaterinburg, em 1918. Quase 80 anos depois, em 1991, foi revelado o achado de ossadas humanas, em escavações, a cerca de $20 \mathrm{~km}$ duma das principais cidades dos Montes Urais - Ekaterinburg, onde a família imperial havia sido mantida prisioneira. Mediante perícia forense concluiu-se que os esqueletos, em estado avançado de deterioração, apresentavam sinais de agressões ante mortem e alguns deles apresentavam mesmo orifícios no crânio. Estudos de antropologia, designadamente de reconstrução facial e odontologia, indicavam que alguns restos ósseos podiam corresponder à família imperial da Rússia (Gill et al., 1994).

Numa primeira fase, o estudo do gene da amelogenina permitiu confirmar o diagnóstico relativo ao sexo dos cadáveres efectuado por métodos antropológicos. Dos nove indivíduos, quatro eram do sexo masculino e cinco do sexo feminino.

A análise de ADN nuclear permitiu, ainda, a obtenção de resultados em 5 STR autossómicos. Resultados estes, que permitiram concluir que cinco dos cadáveres tinham relações de parentesco biológico entre si, designadamente quatro das mulheres e um homem. A análise de ADN mitocondrial permitiu inferir que as quatro 
mulheres poderiam corresponder a uma mãe e três das suas filhas. Esta sequência de ADN mitocondrial obtida foi comparada com a sequência de ADN mitocondrial do sobrinho-neto da Czarina - Príncipe Filipe (consorte da Rainha Isabel II e Duque de Edimburgo), tendo-se confirmado que havia identidade. Estávamos, portanto, perante a Czarina da Rússia e três das suas filhas. O quinto indivíduo, do grupo com relações de parentesco biológico entre si, seria o pai das três filhas, portanto do último Czar da Rússia. Esta constatação foi posteriormente reforçada quando se veio a verificar identidade na heteroplasmia mitocondrial detectada no cadáver do suposto Czar da Rússia e no seu irmão Jorge Alieksándrovich Románov (heteroplasmia 16169).

O estudo de ADN nuclear e mitocondrial dos nove cadáveres encontrados nas escavações acima referidas permitiram confirmar que dois deles eram o Czar e a Czarina da Rússia, e três eram de filhas de ambos. Já no decurso do ano de 2007, foram encontrados restos mortais totalmente esqueletizados, que vieram a ser identificados, pela genética, como sendo os outros dois filhos da família Romanov, numa vala a 70 m do local onde os restos mortais do Czar tinham sido encontrados 30 anos antes (Coble et al., 2011).

$\mathrm{Na}$ investigação de casos de violação dos direitos humanos, os especialistas forenses são frequentemente confrontados com a identificação de restos esqueletizados encontrados em valas comuns. O objectivo principal é, não só a identificação mas também, a determinação de eventuais causas e circunstâncias de morte.

Fazemos aqui uma chamada de atenção para o facto de que na maior parte dos casos de vítimas de guerras, as possibilidades de obter informação é residual, devido ao longo período decorrido entre a morte e a recuperação dos corpos, à ausência de testemunhos e descrições, e devido à qualidade e quantidade de elementos individualizantes preservados, dado que, habitualmente, os corpos encontrados em valas comuns são de grupos relativamente homogéneos, como é o caso de jovens militares, praticamente todos com a mesma idade ou idades aproximadas e todos do sexo masculino.

A título de exemplo de identificação de vítimas de conflitos armados, começaríamos por aludir aos militares mortos durante a II Guerra Mundial (1939 - 1945). Decorridos 60 anos sob o conflito armado, diversos países europeus têm levado a cabo a identificação, pelo estudo de ADN, de restos esqueletizados sepultados em valas comuns. Têm sido utilizados marcadores diferentes, com objectivo comum. Desde STR autossómicos, mini-STR, Y-STR, na Eslovénia (Marjanovic et al., 2007) e Bósnia e Herzegovina (Gojanovic et al., 2007), a ADN mitocondrial na Finlândia (Palo et al., 2007). Uma comissão, nomeada pelo Governo da Eslovénia, sinalizou quase 600 valas comuns, uma das quais, descoberta em 2009, com cerca de 300 vítimas, mortas pelas forças armadas comunistas (Marjanovic et al., 2009).

Também militares americanos, mortos em combate na guerra do Vietname (1959 - 1975), foram identificados, 24 anos pós-guerra, pelo Armed Forces DNA Identification Laboratory (AFDIL). Os restos esqueletizados de alguns dos membros dos serviços militares americanos foram identificados através da análise de ADN mitocondrial, por comparação com as respectivas mães (Holland et al., 1993).

Na última década do século XX (1991 1999), ocorreram conflitos militares na Bósnia 
e Herzegovina, no Kosovo, na Croácia e na ex-Jugoslávia, resultado dos quais, milhares de vítimas foram sepultadas em valas comuns. Só na ex-Jugoslávia, como resultado dos conflitos armados da década de 90 do século passado, cerca de 40000 pessoas foram dadas como desaparecidas, estimando-se que a maioria corresponde a corpos não identificados que permanecem em valas comuns. Em 2000, foi formalmente estabelecido um programa da International Commission of Missing Persons (ICMP) na tentativa de realização da identificação humana através de uma rede que envolve estruturas político-administrativas, centros de contacto de familiares de desaparecidos e laboratórios de estudo de ADN (Huffine et al., 2001). Um número considerável destas vítimas, mais concretamente cerca de 2944 restos esqueletizados de entre 3502 corpos exumados, foi identificado entre 1993 e 2005, tendo ocorrido a maior parte das identificações entre 1993 e 1999, através de métodos antropológicos. Posteriormente à identificação por métodos antropológicos, cerca de 1 155 amostras ósseas foram submetidas a análise de ADN (Andelinovic et al., 2005).

No caso especifico da Guerra Civil Espanhola (1936 - 1939) e no período pós-guerra (1939 1950), estima-se que mais de 150000 indivíduos foram assassinados e sepultados em valas comuns e cemitérios. Desde 2000, através da iniciativa de associações como a Asociación para la Recuperación de la Memoria Histórica (ARMH), foram localizadas diversas valas comuns, exumados os restos cadavéricos e, após identificação genética, sepultados os indivíduos junto dos locais e famílias de proveniência. Em 2004, foram exumados 46 esqueletos de uma vala comum junto a uma pequena cidade na província de Burgos.
A informação relativa à localização da vala, ao número de corpos na mesma, e a lista das possíveis identidades foi obtida a partir de entrevistas realizadas pela ARMH aos familiares e testemunhas, a partir dos registos escritos, em forma de autobiografia, pelos mesmos, bem como a partir da pesquisa ao arquivo penitenciário (como é o caso de 21 homens libertados da prisão e subsequentemente desaparecidos). A pesquisa nos arquivos prisionais, militares e civis, bem como o depoimento das testemunhas permitiu obter dados individuais ante mortem das vítimas. A consistência entre os dados obtidos pelos testemunhos, pelos arquivos, pelo estudo arqueológico e osteológico, permitiu iniciar o estudo de ADN, partindo-se da hipótese de se tratar de um grupo fechado. Dos 46 cadáveres, foram identificados 17 pelo estudo de 16 Y-STR e ADN mitocondrial. (Rios et al., 2010)

Por razões históricas referimos, ainda, a identificação de Che Guevara (Ernesto Rafael Guevara de la Serna), e de membros da guerrilha boliviana dos anos 60 do século passado, cujos restos esqueletizados, foram encontrados em duas valas distintas, por uma equipa de peritos forenses de Cuba, da Argentina e na Bolívia, em 1995. Após o estudo efectuado pela antropologia forense, foi necessária a intervenção da genética, com recurso ao estudo de STR e ADN mitocondrial em segmentos de fémures que estiveram inumados, durante cerca de 30 anos, na Bolívia (Lleonart et al., 2000).

Mais recentemente destacaríamos os ataques terroristas contra os Estados Unidos, em 11 de Setembro 2001, que deixaram mais de 3000 vítimas mortais em três locais diferentes - Pentágono, Somerset County e World Trade Center (WTC) (Budowle et al., 2005). 
Amostras de ADN provenientes do Pentágono e Somerset County foram processadas pelo Armed Forces DNA Identification Laboratory (AFDIL), enquanto que o trabalho relacionado com as vítimas do WTC foi realizado pelo Forensic Biology Department do Office Chief Medical Examiner (OCME), pela Polícia do Estado de Nova York, e por uma série de laboratórios contratados e consultores. Após o colapso e esmagamento das torres do WTC, foram recolhidos cerca de 20000 restos humanos, a partir dos escombros, cujo entulho atingia $21 \mathrm{~m}$ de altura e pesava mais de um milhão de toneladas. A remoção inicial e classificação de restos humanos ocorreram entre Setembro de 2001 e Maio de 2002. Os estudos de ADN foram efectuados em diversos laboratórios que analisaram cerca de 20000 fragmentos de tecidos humanos, relativos a 2749 pessoas desaparecidas, além dos 5000 objectos de uso pessoal e cerca de 6000 familiares. Os restos recuperados no local do WTC estavam muito fragmentados, por terem sido submetidos, a pressões extremas com o colapso do edifício, ao combustível derramado dos aviões, a incêndios subterrâneos (com mais de $815^{\circ} \mathrm{C}$ ), durante os 3 meses seguintes ao ataque terrorista. Neste caso específico, para a identificação das vítimas, a intervenção da Genética foi preponderante e imprescindível, dado o grau de fragmentação dos restos, colapso e agregação de remanescentes cadavéricos de vítimas.

Um dos maiores desafios desta investigação foi a revisão da quantidade abissal de dados produzidos pelos laboratórios colaboradores e contratados. No esforço inicial entre 2001 e 2005, foram obtidos mais de 52528 perfis de STR e 31155 sequências de ADNmt, com base nos 21
802 remanescentes recuperados, na tentativa de identificar as 2749 vítimas. No entanto, em 5335 das amostras biológicas recuperadas, obtiveram-se apenas perfis incompletos de STR ( 1 a 6 loci dos 13 pretendidos), na primeira fase, tornando ainda mais difícil organizá-los e juntar informações suficientes para uma identificação fiável. Na segunda fase foi possível obter 154 perfis completos e 388 perfis parciais mas com presença de alelos na maioria dos loci, após nova extracção com o métodos modificados. Até Junho de 2010, foi conseguida a identificação de 1626 vítimas, das 2749 presentes quando as Torres desmoronaram.

Como o estudo de ADN é o único método que permite reagrupar restos humanos, do total de 21802 remanescentes recolhidos, foram identificados 12769 fragmentos humanos, e respectivamente correlacionados com uma das 1626 vítimas identificadas (Butler, 2011).

Várias inovações foram desenvolvidas nesta área, após o atentado ao WTC. Foi desenvolvido o novo sistema bioinformático Mass Fatality Identification System (M-FYSis) que permite, em grande escala, comparações de perfis das amostras de referência e restos recuperados bem como associar os fragmentos com o mesmo perfil de ADN. Possibilita uma série de funcionalidades e interoperabilidade, integrando diferentes sistemas de software (Budowle et al., 2005; Butler, 2011).

$\mathrm{O}$ acto de terrorismo a 11 de Março de 2004, em Madrid provocou um acidente ferroviário com dezenas de feridos e vítimas mortais. No processo de identificação de cadáveres, foi utilizada a Base de dados do Sistema CODIS para comparar os restos de 220 corpos com 98 amostras de referência, incluindo 67 amostras de familiares, representando 40 grupos familiares, e 
27 amostras de referência directas antemortem. (Alonso, 2005)

Já em Dezembro de 2004, o Tsunami do Oceano Índico, ocorrido no Sul da Ásia Oriental, foi uma catástrofe natural que afectou 12 países, dos quais a Tailândia, a Índia, a Indonésia e o Sri Lanka, e do qual resultou a morte de mais de 200 000 pessoas, com vítimas oriundas de 30 países. Neste desastre, os cadáveres recuperados, apesar de não apresentarem fragmentação, encontravam-se em avançado estado de decomposição, devido às condições de clima tropical a que ficaram expostos. O desaparecimento de familiares ou famílias inteiras, limitou a possibilidade de comparação com amostra de referência de familiar ou directa, visto os objectos pessoais também ficarem destruídos. Investigadores forenses de 31 países diferentes chegaram à Tailândia para ajudar na identificação das vítimas da catástrofe (Westen et al., 2008)). Uma primeira abordagem à identificação das vítimas do Tsunami com recurso ao ADN teve lugar no Leipzig Institute of Legal Medicine, tendo, posteriormente, os estudos prosseguido no Forensic Alliance, em Inglaterra, no Institute for Forensic Genetics, na Suécia, no Bejing Genomics Institute, na China e no ICMP, na Bosnia e Herzegovina (Lessing \& Rothschild, 2011). Em Maio de 2005 teriam sido identificadas mais de 1400 vítimas e repatriadas para mais de 34 países (Butler, 2011).

Muito recentemente, procedeu-se à recolha de centenas de remanescentes humanos das valas comuns encontradas no Kuwait e Iraque, resultado da Guerra do Iraque. Nos primeiros cinco anos, pela análise de ADN, foram identificados 233 cadáveres (Butler, 2011).

\section{3. ÂMBITO DE APLICAÇÃO DA IDENTIFICAÇÃO GENÉTICA DE DESCONHECIDOS}

Genericamente, em termos quantitativos, podem ser-nos presentes, para identificação genética, indivíduos isolados, vivos ou em estado de cadáver, ou remanescentes humanos, com origem num único indivíduo, ou em múltiplos indivíduos, sendo estes vítimas de mortes naturais; como doença ou outros factores intrínsecos ao indivíduo; ou mortes violentas, onde podemos distinguir suicídio, homicídio ou acidente. Destacaríamos, aqui, as vítimas de acidentes rodoviários, naufrágios, incêndios, explosões, derrocadas, de entre outros.

Introduziríamos agora o conceito de desastre de massas, que, segundo a Organização Mundial de Saúde (OMS) só tem lugar quando ocorre um fenómeno de magnitude suficiente para implicar a assistência externa. Podemos estar perante desastres de massas nos casos de acidentes de aviação, de catástrofes naturais, conflitos bélicos ou políticos, atos terroristas, nos quais o número de vítimas para identificação genética pode ser muito elevado.

Em quaisquer dos casos acima referidos, podem ser presentes para identificação genética, indivíduos vivos indocumentados, cadáveres frescos mutilados, cadáveres em diferentes estados de decomposição, maioritariamente esqueletizados, ou remanescentes cadavéricos.

Podem, ainda, ser-nos presentes, para identificação genética, remanescentes de interrupções de gravidez, remanescentes fetais, fetos, recém-nascidos e amostras dúbias, a maior parte das quais são amostras clínicas 
como sangue ou biopsias dos mais diversos tipos de tecidos humanos, para confirmação de a quem pertencem as referidas amostras clínicas. Em relação às amostras dúbias, estas podem surgir em sequência do diagnóstico de uma patologia mas também de um exame toxicológico, designadamente exame de determinação de alcoolémia ou determinação de drogas de abuso no âmbito de controlos anti-dopping em atletas. Em qualquer destes casos, sempre que um indivíduo a quem foi associado determinado diagnóstico ou a quem é imputado o consumo de determinada substância entende haver dúvidas quanto ao facto de a amostra ser a que Ihe foi colhida, pode, desta dúvida, resultar um processo de identificação do indivíduo a quem, de facto, a amostra pertence.

Relativamente à identificação de restos fetais ou embrionários, a lei portuguesa prevê que deve ocorrer após interrupção da gravidez ordenada, em sequência de uma violação (artigo 42. ${ }^{\circ}$ do Código Penal Português), por comparação com amostra relativa ao agressor/presumível progenitor.

Já nos casos em que há suspeita de um nado vivo ou morto ter sido abandonado pela mãe, o material biológico é estudado, quase sempre, para esclarecimento da maternidade biológica.

Aproveitaria aqui para deixar a ressalva de que quer os restos fetais ou embrionários, quer tecidos placentários provenientes de nados vivos ou mortos contêm, regra geral, quantidades muito apreciáveis de ADN, pelo que devem ser rapidamente congelados, sem quaisquer conservantes, como álcool ou formol, para evitar a sua eventual degradação.

\section{OS DIFERENTES TIPOS DE AMOSTRAS PROBLEMA ESTUDADAS}

A selecção das amostras, do ou dos cadáveres e do ou dos restos humanos, depende do estado de preservação e fragmentação do cadáver.

A preservação é determinada, muito especialmente, pela actuação de factores ambientais, durante o tempo que decorre desde a morte até à colheita.

Os cadáveres sofrem processos autolíticos, por actuação enzimática, e processos de putrefacção, por fermentação da matéria orgânica, pela acção de microrganismos, por acção de determinadas espécies de insectos e por acção de outros animais.

Em relação ao material genético, degrada-se mais rapidamente, nos tecidos moles do que nos tecidos ósseos, devido à estrutura histológica destes, que proporciona maior isolamento às células ósseas.

Nos dentes, a presença do tecido conectivo que oferece protecção física à polpa dentária - esmalte, e que é o tecido mais resistente de qualquer organismo, confere especial protecção à degradação e contaminação do ADN.

Para além da estrutura histológica, a densidade tecidular também é um factor importante que influencia a preservação do osso. Desta forma, o ADN é geralmente menos degradado nas porções mais densas do esqueleto que em qualquer outro tecido (Mundorff et al., 2009).

Apesar da região esponjosa do osso ser a mais rica em ADN, é da região mais compacta que, habitualmente, é escolhida uma amostra dos ossos longos dos membros inferiores, para estudo pela genética forense. 
O estudo realizado a 25361 amostras de ossos e dentes, recuperados de vítimas sepultadas entre 4 a 11 anos, em valas comuns, na exJugoslávia, indicou que o ADN é melhor preservado no fémur e dentes, seguido por tíbias, fíbulas, úmeros, crânios e rádios (Milós et al., 2007).

Em restos humanos fragmentados, onde, contudo, ainda subsistem tecidos moles, dependendo do estado de putrefacção, os tecidos de órgãos (bexiga, artéria aorta) ou o músculo esquelético profundo, são amostras de eleição para extração de ADN (Schwarkt et al., 2011).

Quando o cadáver está esqueletizado ou em avançado estado de decomposição, as amostras úteis são ossos longos, dentes não tratados (por ordem preferencial, molares, pré-molares, caninos e incisivos) ou unhas.

As unhas são formadas por células que contêm queratina, devendo-se o seu crescimento à divisão celular na base e parte interna da unha. Estas células migram para o exterior enquanto sofrem um processo de reabsorção do núcleo e dos organelos celulares.

Num cadáver putrefacto desconhecido, deve-se retirar ou desinserir unhas inteiras, obtendo-se na prática bons resultados na análise de ADN. As unhas têm permitido a identificação cadavérica de forma rápida, com recurso a métodos de extracção menos complexos e morosos, comparativamente ao tratamento a ter com as amostras ósseas.

Este tipo de amostra é muito utilizado no caso de exumações, sendo retirado preferencialmente as unhas dos pés ao cadáver, por estarem mais protegidas pelo calçado, portanto, com menor possibilidade de degradação/ contaminação.
Nos cadáveres queimados, qualquer das amostras descritas pode ser válida, dependendo do estado de carbonização. Na maioria destes casos, tem sido possível obter quantidade apreciável de ADN, a partir de fragmento de tecido, de zonas profundas, da área melhor conservada (como musculo cardíaco, sangue sólido de interior de cavidades cardíacas, fígado, bexiga).

Nos remanescentes de cadáveres, encontrados submersos, a possibilidade de se conseguir bons resultados é remota, uma vez que o estado de degradação é muito maior.

Num cadáver não decomposto, o sangue é o tipo de amostra colhida.

\section{AS AMOSTRAS DE REFERÊNCIA A UTILIZAR NA IDENTIFICAÇÃO GENÉTICA}

Não é possível efectuar qualquer identificação, através da análise de ADN, se não se dispuser de amostras de referência. Estas podem ser de familiares ou amostras do próprio indivíduo, como objectos pessoais (escova de dentes, lâminas de barbear) ou amostras biológicas colhidas ante mortem existentes em arquivo, como tecidos de biopsias, bancos de esperma ou manchas de sangue em cartões. Outra hipótese é a existência de perfil numa base de dados civil ou criminal, no país da vítima (Corte-Real, 2004). Em Portugal, foi oficialmente instituída, em 2008, uma base nacional designada Base de Dados de Perfis de ADN, cuja direção cabe ao Instituto Nacional de Medicina Legal e Ciências Forenses (INMLCF).

A utilização de objectos de uso pessoal pode ser problemática, pelo facto da quantidade de 
ADN ser mínima, bem como pela possibilidade de conter ADN não apenas da vítima, obtendo-se perfis de mistura, dado não haver garantia do objecto ter sido só usado pela vítima. O inconveniente desta estratégia, é comprometer a identificação, conduzindo a falsas exclusões, devido à contaminação exógena de células de outros contribuidores. Sendo questionável a autenticidade dos objectos, é sempre recomendável, caso seja possível, a colheita de outras amostras (de membros da família) para análise e comparação (Pinheiro, 2009).

A possibilidade de usar amostras de referência do próprio indivíduo, colhidas ante mortem (como os cartões de sangue de recém nascidos relativos a programas de rastreio de doenças genéticas) com cadeia de custódia documentada, ultrapassa os inconvenientes dos objectos pessoais. Em diversos países, a existência de um arquivo de cartões de manchas de sangue dos militares mobilizados para conflitos armados é recomendado para facilitar a identificação em caso de eventual acidente (Alonso et al., 2005).

As amostras de referência de familiares dependem do tipo de estudo de ADN a realizar. O estudo de STR autossómicos (13 a 17), marcadores com elevado poder discriminatório, permite a identificação precisa, mediante comparação com amostras de familiares directos da vítima: (a) progenitores da vítima, (b) filhos biológicos e cônjuge da vítima (c) vários irmãos com os mesmos pai e mãe.

Se não dispomos destas amostras de familiares directos ou não é possível estudar os marcadores de ADN autossómico, os marcadores monoparentais podem ser úteis. Com a análise dos marcadores do cromossoma Y, cuja herança é exclusivamente do pai para filhos do sexo masculino, as amostras de referência para comparação são amostras de todos os familiares relacionados por via paterna. O ADN mitocondrial, de herança exclusivamente materna, permite a comparação com parentes relacionados por via materna.

\section{ESTUDO LABORATORIAL E VALORIZAÇÃO ESTATÍSTICA DE RESULTADOS}

\subsection{EXTRACÇÃO DE ADN E TRATAMENTOS PRÉVIOS}

Quanto à extracção de ADN de amostras de referência, designadamente manchas de sangue em suporte de papel e células da mucosa oral em zaragatoa, em que, a priori sabemos ter ADN em quantidade e qualidade, o método de extracção mais utilizado internacionalmente é o método de Chelex (Walsh et al., 1995). Genericamente é um método de extracção que recorre ao factor temperatura para alcançar a extracção de ADN e utiliza um elemento inerte, o Chelex, para retenção e isolamento de restos celulares numa solução em que se pretende que só o próprio ADN se mantenha como soluto.

Neste momento será importante realçar que a extracção das amostras de referência, para evitar a contaminação no percurso laboratorial, deve-se realizar de forma separada, em tempo e espaço, da extracção das amostras problema.

No processo de análise de ADN, a extracção é um passo crucial, com especial destaque para a extracção de ADN de amostras problema. A recuperação máxima de ADN, em termos de 
qualidade, quantidade e pureza, depende, em grande parte, dos métodos de extracção. Para os restos cadavéricos e objectos pessoais, que possam ser amostras com ADN em pequenas quantidades e muito degradado, é essencial uma escolha especialmente criteriosa do método de extracção, e a sua optimização, dado que a selecção do método de extracção depende sempre, também, do tipo de amostra e do seu estado de conservação.

Um problema, não raramente associado a determinadas amostras, é o facto de, apesar de conterem ADN em quantidade suficiente, terem presentes, também, determinados componentes, que inibem a amplificação de ADN. Nestes casos, os métodos de extracção a utilizar devem minimizar a perda do ADN e remover inibidores.

Em relação ao caso específico de extracção de ADN a partir de amostras ósseas e dentes, esta requer, ainda, equipamentos, reagentes e procedimentos específicos. Os tratamentos prévios à extracção incluem a cuidadosa lavagem dos ossos para remoção de terra e de outros materiais aderentes, como restos de tecidos moles putrefactos. Quanto mais limpo estiver o osso, melhores resultados obteremos uma vez que a eliminação de eventuais contaminantes presentes na superfície do osso, foi mais eficaz. Há diversos métodos de limpeza da superfície do osso, desde utilização de lixa, bisturis, serra eléctrica, irradiação da superfície com raios UV e/ou a aplicação de soluções químicas com detergentes, etanol, lixívia, de entre outros.

A imersão do osso, numa solução de hipoclorito de sódio a $2 \%$, durante 10 minutos, destrói a contaminação superficial, resultando na degradação do ADN indesejável presente na superfície do osso (ADN exógeno, provavelmente das pessoas que o manipularam e ADN microbiano) (Pinheiro, 2009; Westen et al., 2008).

A limpeza ou remoção da superfície do osso, até que este fique limpo, a sua posterior redução a fragmentos com cerca de $1 \mathrm{~cm}^{2}$, através do uso de serra eléctrica, e, finalmente, a pulverização dos ossos (redução do osso a pó), a baixas temperaturas, com recurso a azoto líquido, são procedimentos obrigatórios, antes da extracção de ADN. O material ósseo reduzido a pó deve ser retido em recipientes próprios para o efeito (habitualmente ampolas), também, para impedir contaminações.

Os métodos de extracção de ADN mais frequentemente utilizados são métodos baseados na utilização de fenol-clorofórmio-álcool isoamílico, enzimas e sílica. Basicamente, as enzimas, bem como uma grande parte de soluções/tampões a que estes métodos recorrem, têm por função a lise de membranas celulares e outras estruturas de natureza proteica, para libertação do ADN. A sílica é um material inerte cuja função é a retenção e isolamento do ADN dos restantes componentes celulares em solução.

Na extracção de ADN das amostras ósseas das vítimas do conflito armado dos Balcãs (1992 - 1995), com vista à identificação genética, foram documentados melhores resultados na extracção com recurso a sílica comparativamente à extracção com fenol-clorofórmio-álcool isoamílico (Davoren et al., 2007). A extracção com métodos baseados em sílica permitiu, também, a identificação de remanescentes ósseos de 15 vítimas da II Guerra Mundial, encontradas em vala comum, na Eslovénia, em 2007 (Marjanovic et al., 2007) e de outras 6 vítimas em 2009 (Marjanovic 
et al., 2009). Nas perícias da rotina do INMLCF, utilizamos, muito frequentemente, os métodos baseados em princípios enzimáticos e sílica, com resultados muito satisfatórios.

Após a extracção do ADN das amostras ósseas ou outras amostras problema, a quantidade de ADN recuperado deve ser determinada, sempre que possível. Conhecer a quantidade de ADN para a reacção de $P C R$, pode favorecer a obtenção de melhores resultados analíticos, ou, por outro lado, pode dar-nos informação de que não foi possível obter ADN, pelo que, não terá utilidade prosseguir com métodos de análise de ADN.

\subsection{MARCADORES DE ADN ESTUDADOS POR PCR E PERFIS GENÉTICOS}

\section{ADN nuclear (STR), ADN mitocondrial}

(ADNmit), mini-STR e SNPs

Após extracção de ADN das amostras a estudar, as mesmas são amplificadas, pela técnica de PCR, com iniciadores específicos para determinados marcadores.

Genericamente, quanto à sua localização, distinguem-se dois tipos de ADN: o ADN nuclear e o ADN extra-nuclear. O extra-nuclear é o ADN mitocondrial.

Relativamente ao ADN nuclear, quanto ao número de cópias das suas sequências ou fragmentos, ele pode agrupar-se em diferentes categorias. Assim temos sequências de ADN de cópia única e sequências de ADN com multi-cópias. Quanto às sequências de ADN com multi-cópias temos sequências com cerca de 300 pares de bases que se repetem entre 100 a 100000 vezes ao longo do genoma (ADN moderadamente repetitivo) e temos sequências de ADN altamente repetitivas, também conhecidas por ADN satélite, que se repetem mais de 100000 vezes ao longo do genoma. Estas últimas são sequências pequenas, de 1 a 50 pares de bases e são sequências de ADN não codificante. É deste grupo que fazem parte os microssatélites ou Short Tandem Repeats (STR), que são, actualmente, os marcadores de eleição, utilizados a nível internacional, no âmbito da identificação genética, muito especialmente devido ao seu elevado poder discriminatório inter-indivíduos e, portanto, elevado poder de individualização.

O Conselho da União Europeia, por Resolução de 25 de Junho de 2001, estabeleceu um conjunto de 7 loci, designado por European Standard Set (ESS), como conjunto de loci adequado à definição de um perfil genético individual, constituído pelos STR autossómicos D3S1358, FIBRA, D8S1179, TH01, vWA, D18S51, D21S11.

No âmbito da investigação criminal, a Interpol, utiliza os 7 loci do ESS e, opcionalmente, o gene homólogo da amelogenina.

O Reino Unido utiliza os 7 loci do ESS e mais 4 loci, portanto, utiliza um conjunto de 11 loci - D2S1338, D3S1358, FIBRA, D8S1179, TH01, vWA, D16S539, D18S51, D19S433, D21S11 e o gene homólogo da amelogenina.

A Alemanha utiliza os 7 loci do ESS e mais 2 loci, portanto, um conjunto de 9 loci - D3S1358, FIBRA, D8S1179, TH01, vWA, D18S51, D21S11, SE33 e o gene homólogo da amelogenina.

Os Estados Unidos da América utilizam os 7 loci do ESS e mais 6 loci, portanto, utilizam um conjunto de 13 loci STR autossómicos para definição de um perfil genético individual, designado por painel de STR do Combined DNA Index 
System (CODIS), composto pelos loci autossómicos TPOX, D3S1358, FIBRA, D5S818, CSF1PO, D7S820, D8S1179, TH01, vWA, D13S317, D16S539, D18S51, D21S11. Além destes 13 loci autossómicos o sistema CODIS inclui sempre informação do gene homólogo da amelogenina (Butler, 2005).

No INMLCF são utilizados os 13 loci STR do sistema CODIS e mais 4 loci autossómicos D2S1338, D19S433, Penta D e Penta E (Amorim et al., 2011b), e, em casos especialmente complexos, designadamente casos em que só se verifica incompatibilidade em dois loci, estudam-se, ainda, como loci adicionais, os loci STR autossómicos SE33, ES, LPL, F13B, FESFPS, F13A01, D10S1248, D22S1045, D2S441, D1S1656 e D12S391, e, caso seja aplicável, estudam-se também 16 loci STR do cromossoma $Y$, onde, além dos 8 marcadores que definem o designado haplótipo mínimo - DYS19, DYS385, DYS389I, DYS389II, DYS390, DYS391, DYS392, se incluem mais 8 loci - DYS437, DYS438, DYS439, DYS448, DYS456, DYS458, DYS635 e GATAH4. Em casos muito específicos estudam-se, ainda, a região hipervariável I (HVI) e a região hipervariável II (HVII) do ADN mitocondrial (ADNmt).

Recentemente, em finais de 2009, o Conselho da União Europeia, por Resolução de 30 de Novembro, redefiniu o conjunto dos loci que integram o ESS. Os loci que integram o actual ESS são os STR autossómicos D3S1358, FIBRA, D8S1179, TH01, vWA, D18S51, D21S11, D1S1656, D2S441, D10S1248, D12S391 e D22S1045. Contudo, como ainda não existem frequências alélicas calculadas e publicadas para os novos STR, continuam a ser utilizados, no INMLCF, os STR atrás mencionados.

Quando não é possível obter um perfil de ADN nestes marcadores nucleares, procede-se à análise de ADN mitocondrial. Uma das principais vantagens do ADNmt, em relação ao ADN nuclear (2 cópias por célula), consiste no facto de possuir cerca de 500-2000 cópias por célula, o que aumenta as probabilidades de existirem algumas cópias mesmo em amostras forenses muito degradadas e/ou antigas. O comprimento do ADNmt (100000 vezes inferior ao ADN nuclear) e a sua forma circular também Ihe conferem uma menor probabilidade de degradação em relação ao ADN nuclear.

Outras vantagens do ADNmt, consiste no facto de este ser herdado por via materna, ou seja, todos os indivíduos pertencentes à mesma linhagem materna, possuem o mesmo ADNmt (excepto na presença de mutações). Assim, mesmo que só existam familiares por via materna, estes podem fornecer amostras referência com vista à identificação. A análise pelo ADNmt é de grande utilidade, quando várias gerações separam as vítimas dos seus descendentes vivos, como os casos de desaparecidos durante décadas, decorrentes de conflitos políticos ou de guerras (Afonso-Costa et al., 2010).

No entanto, os marcadores haplotípicos (ADNmt e cromossoma $Y$ ) apresentam baixo poder de discriminação, em comparação com o poder de discriminação que proporcionam os marcadores autossómicos, o que leva a um menor grau de certeza na identificação final. Neste sentido e para reforçar a identificação deve-se empregar/utilizar a análise de ADNmt e de cromossoma Y (quando se trate de vítimas do sexo masculino) de forma conjunta, estabelecendo-se para eles os irmãos do sexo masculino como familiares de eleição a integrar no estudo (Crespillo, 2011).

As amostras com ADN muito degradado ou em quantidades ínfimas poderiam ser sujeitas a 
análise de regiões/segmentos com dimensões inferiores a 150 pares de bases - os miniSTR. Estes marcadores genéticos foram desenvolvidos através da modificação dos primers para amplificação dos STR, que passam a delimitar regiões interiores e, portanto, menores às regiões definidas para os STR.

Quando no genoma ocorre uma mutação pontual, originando uma variação num único par de bases, estamos perante aquilo que definimos como polimorfismo num único nucleótido ou Single Nucleotide Polymorphism (SNP). Num único indivíduo acontecem milhões de SNP, consolidando a ideia de que poderão vir a ser considerados, pela comunidade forense, como marcadores genéticos. A sua eventual vantagem em relação aos STR é o tamanho dos produtos de PCR, que apresentam menos de 100 pares de bases, quando comparados com os 300 a 400 pares de bases dos STR, possibilitando assim, o seu uso em material com ADN degradado. No entanto são mais laboriosos e muito menos discriminatórios, visto ser necessário 45 a 50 loci SNP, para um resultado discriminatório comparável a 13 a 15 loci STR (Ziętkiewicz, 2011).

\subsection{VALORIZAÇÃO ESTATÍSTICA}

\section{DOS RESULTADOS}

Após a obtenção dos perfis genéticos, a valorização estatística dos resultados pode ter, de acordo com o caso em concreto, e muito genericamente, duas abordagens.

Se é possível comparar o perfil obtido a partir do cadáver ou dos restos humanos com o perfil da suposta vítima (caso em que existia amostra de referência ante mortem) temos como resultados possíveis a identidade ou a não identidade entre os perfis. No caso de haver identidade entre os perfis é calculada a razão de verosimilhança ou Likeliwood Ratio (LR), conforme descrito num outro capítulo inserto nesta obra, e que traduz a probabilidade do perfil da vítima corresponder, de facto, ao perfil da suposta vítima.

Se não é possível comparar o perfil obtido a partir do cadáver com o perfil do suposto indivíduo, mas, alternativamente, é possível comparar com os perfis de supostos familiares, os cálculos a realizar têm em vista a determinação dos parâmetros Probabilidade de Parentesco e Índice de Parentesco, entre a vítima e os supostos familiares (Ge et al., 2011). Estes cálculos e parâmetros estatísticos estão, também, explanados em capítulo dedicado à investigação de parentesco biológico, também, inserto nesta obra.

\section{OS PRINCIPAIS PROBLEMAS RE- LACIONADOS COM AS AMOSTRAS EM ESTUDO}

\subsection{DEGRADAÇÃO}

A degradação do ADN pode dividir a molécula em fragmentos mais pequenos, impedindo a obtenção de resultados, ou a obtenção de perfis genéticos incompletos ou mesmo levar a que ocorra o desaparecimento de um dos alelos, com atribuição incorrecta de homozigotia em alguns sistemas.

A degradação do ADN começa imediatamente após a morte de um organismo, e irá continuar, a velocidades diferentes, dependente do meio ambiente envolvente.

A degradação post mortem ocorre, via a acção das nucleases endógenas, enzimas celulares 
que catalizam a hidrólise das ligações fosfodiester na molécula de ADN.

No ADN antigo verificou-se que os fragmentos obtidos estão entre 100 bp a 200 bp de tamanho, sugerindo que a clivagem enzimática ocorre em regiões de ligação vulneráveis, situadas entre nucleossomas da estrutura terciária do ADN.

Para a preservação de algum ADN, é necessário que a acção destas enzimas biológicas seja diminuída ou inactivada, antes que ocorra a degradação completa.

A preservação do ADN em restos está dependente de uma interacção complexa de condições ambientais, incluindo a exposição a temperatura, humidade, radiação UV, fogo, microorganismos, flora, fauna e propriedades geoquímicas do solo.

Processos de oxidação e hidrolíticos provocam lesões na estrutura da molécula, respectivamente, modificação das bases nitrogenadas e modificação no açúcar "desoxiribose". As alterações químicas das bases nucleotídicas conduzem ao não reconhecimento pela Taq polimerase na reacção de PCR. A perda de informação genética disponível impede a amplificação do ADN e consequentemente a não obtenção de resultados.

A presença de bactérias e fungos contribuem para a degradação do ADN, não só por digestão, mas também aumenta o risco de contaminação da amostra por ADN exógeno.

Em relação à composição dos solos, constatou-se que os ácidos húmicos e fúlvico são inibidores da amplificação do ADN. A presença destes ácidos, no ambiente em que os restos esqueletizados estão enterrados, tem correlação directa com a humidade da área. A humidade, temperatura e solo promovem degradação do ADN de forma célere, permitindo que as substâncias orgânicas dos sedimentos penetrem nos tecidos ósseos (Graham, 2007).

Circunstâncias favoráveis como baixa temperatura, dissecção, pH alcalino ou neutro, concentração elevada de sais e ausência de microrganismos destrutivos e contaminantes são as melhores condições para a preservação do ADN. Climas frios e secos tendem a preservar macromoléculas por longos períodos de tempo, devido a taxas de reacção mais lentas (supostamente, por inactivação das nucleases endógenas e exógenas).

Os dados revelam que não há correlação directa entre preservação do ADN e o tempo decorrido. Condições favoráveis podem evitar o dano físico e químico, permitindo a detecção de ADN nuclear e mitocondrial, após longo período de tempo.

Exemplos são a obtenção de ADN em múmias siberianas, chinesas, bem como no "Homem do Gelo" encontrado nos Alpes austríacos por alpinistas a 3200 m, em Setembro de 1991, identificado como pré-histórico, pelo Innsbruck Forensic Medicine Institut. A mumificação é um fenómeno de preservação excepcional, ao contrário dos corpos embalsamados, cujos conservantes, como o formol, degradam a molécula.

Os cadáveres expostos a climas tropicais, sofrem degradação rápida em curto período de tempo, como as ossadas de portugueses trasladadas de países lusófonos, como Angola, Moçambique, Guiné, Cabo Verde e São Tomé.

\subsection{CONTAMINAÇÃO}

Começamos por distinguir vários tipos de contaminação, designadamente contaminação química, que pode traduzir-se em resultados 
inconclusivos ou ausência de resultados, contaminação provocada por microrganismos (bactérias e fungos), caso em que quantidades apreciáveis de ADN microbiano interferem na quantificação do ADN conduzindo a resultados falso negativos e, finalmente mas não menos importante, a contaminação por ADN humano exógeno, sendo este o tipo de contaminação mais importante, e que pode ocorrer durante ou depois da colheita das amostras.

As contaminações podem ocorrer em todas as etapas do processo, desde a amostragem no local onde a vítima ou amostras são encontradas, até ao procedimento de laboratório. A contaminação pode, ainda, ocorrer no próprio corpo, durante a recolha das evidências, durante o transporte do corpo para os serviços médico-legais, na sala de autópsia e, naturalmente, durante os procedimentos de laboratório.

No local, as contaminações podem ocorrer se outros indivíduos chegam e começam a manipular as evidências sobre o corpo antes da chegada da equipa forense de investigação (Vieira, 2011).

As contaminações representam uma das maiores limitações na análise de ADN, quer na obtenção de perfis válidos quer na interpretação precisa dos resultados. Diversas estratégias têm sido desenvolvidas para ultrapassar as dificuldades que ocorrem no processo. Uma das exigências a ter sempre presente pelo perito, entre outras, é o uso de luvas descartáveis. É igualmente importante a utilização dos meios adequados na colheita, acondicionamento e transporte das amostras da vítima e, numa fase posterior, na totalidade do percurso laboratorial. Relativamente a este assunto há normas perfeitamente determinadas que devem ser tomadas em consideração com redobrado rigor, muito particularmente nos casos em que se está a lidar com amostras complexas, designadamente ADN antigo - amostras com material genético escasso e/ou degradado, ou amostras com inibidores.

Em relação aos casos de identificação de elevado número de vítimas, designadamente resultante de desastres de massa, em que as condições de trabalho estão muito longe das ideais, a colheita de um grande número de amostras de vários indivíduos aumenta o risco de contaminação exógena pelos examinadores e, em particular, de contaminação cruzada com o ADN de outras vítimas. Visto que o Guia da Interpol de Identificação das vítimas não tem guidelines específicas na coIheita de amostras para estudo de ADN, uma das equipas da Thai Tsunami Victim Identification (TTVI) criou guidelines para a colheita de amostras de ossos e dentes com fins de análise de ADN, descrevendo um procedimento operacional com base na experiência adquirida durante o rescaldo do Tsunami. Este Standard Operating Procedure (SOP) foi projectado, essencialmente, para minimizar a contaminação cruzada durante a colheita das amostras (Westen et al., 2008).

Como outros exemplos de cuidados para evitar contaminações podemos ainda referir a estandardização das metodologias de colheita de amostras, a obtenção de perfis de todas as pessoas envolvidas no estudo para o fácil reconhecimento da contaminação proveniente destes profissionais, o uso de ferramentas para evitar contaminações como capuz, rede de cabelo e máscaras na boca, para todos os investigadores responsáveis pela etapa de amostragem, a descontaminação cuidadosa de todos os dispositivos em contacto físico com a amostra, a utilização de 
material descartável livre de ADN, limpeza e irradiação por UV de todos os aparelhos, recipientes, pipetas, suportes, placas, batas de laboratório e áreas de trabalho. É ainda importante que as diferentes etapas do processo de análise tenham lugar em diferentes salas dentro do laboratório, desde o exame macroscópico da amostra ao procedimento de extracção, a reacção de amplificação de ADN e, finalmente, a interpretação dos perfis. Todos os equipamentos gerais e aparelhos, pipetas, bem como os reagentes deverão ser exclusivos de cada sala específica (salas de extração, pré-PCR e pós-PCR) (Vieira, 2011).

\section{CONCLUSÃO}

A identificação humana é de suma importância no âmbito médico-legal, constituindo uma prioridade, tanto por imperativos legais como por razões humanitárias, sendo que, no âmbito da mesma, a identificação genética desempenha um papel importante na identificação de cadáveres esqueletizados, restos humanos, cadáveres recentes, que apresentem mutilações, em particular mutilações faciais, e em indivíduos vivos indocumentados que não tenham, ou afirmem não ter, memória da sua identidade, bem como em restos fetais ou recém-nascidos, amostras dúbias e, muito especialmente, amostras biológicas de vítimas de desastres de massa.

Atenta a importância e relevância da identificação genética de desconhecidos, em 2007, a DNA Commission da ISFG publicou um documento com recomendações para a área da genética forense no âmbito das equipas Disaster victim identification (DVI). Logo a primeira recomendação salienta a inclusão dos laboratórios forenses na planificação da actuação das equipas multidisciplinares DVI, por forma a assegurar a participação dos mesmos na tomada de decisões sobre a coIheita de amostras, extensão e objectivos finais, com vista à maior eficácia da eventual identificação genética.

Há circunstâncias específicas e diferentes factores inter-relacionados, envolvidos em cada cenário de desastre de massa, que podem determinar o objectivo da identificação recorrendo à análise de $A D N$, tais como o número das vítimas, os mecanismos de destruição dos corpos, grau de fragmentação, grau de degradação do ADN, acessibilidade ao corpo para a colheita de amostra ou o tipo e disponibilidade de amostras de referência.

Já em relação à extensão da actuação, visa definir se a análise de ADN é para identificar cada vítima ou apenas um subconjunto das vítimas (por exemplo aqueles que não estão identificados por outros métodos forenses) ou se é imprescindível identificar todos os restos humanos recuperados.

Uma das recomendações da ISFG aconseIha a recolha de amostras para eventual análise de ADN, mesmo quando as identificações foram realizadas por outros métodos forenses. Neste caso, por regra, o objectivo será, eventualmente, permitir a re-associação de fragmentos do corpo e, no futuro, em caso de dúvidas ou contradições, permitir análise de ADN.

A identificação genética de um indivíduo é realizada pela determinação do seu perfil genético individual, o qual é obtido pela determinação da combinação das características genéticas que este indivíduo apresenta num determinado conjunto de marcadores estudados no seu genoma, 
marcadores estes que, actualmente, a nível internacional são loci STR autossómicos e, caso seja aplicável, loci STR do cromossoma Y. Em casos muito específicos estudamos, ainda, a HVI a HVII do DNAmt e, também, mini-STR e SNPs.

Como apontamento, os marcadores genéticos actualmente mais utilizados - loci STR e DNAmt, são aceites pela comunidade científica forense internacionalmente. Para tanto, contribuiu a identificação da família imperial Romanov, que constituiu um marco histórico nas ciências forenses. Paradoxalmente, a morte do último Czar da Rússia e de toda a família imperial e a subsequente instauração do regime soviético, mudou o rumo da História da Humanidade.

Finalmente, reforçaríamos a importância de que os procedimentos no âmbito da identificação genética de desconhecidos, desde a colheita de amostras problema a cadáveres ou restos humanos, bem como a colheita de amostras de familiares de supostos indivíduos a identificar, associadas às quais a obrigatoriedade de existência de documentação que assegure a cadeia de custódia das amostras, passando por todos os procedimentos laboratoriais aplicáveis, até à elaboração do relatório pericial, devem pautar-se pelo cumprimento de normas e regulamentos que assegurem a garantia da qualidade dos resultados obtidos, designadamente através da realização de procedimentos, em particular os de natureza laboratorial, em laboratórios e através de ensaios acreditados.

Terminamos, fazendo a ressalva de que o modesto contributo que aqui quisemos deixar não se apresenta como um referencial técnico ou científico sobre a identificação genética de desconhecidos, mas sim como um documento acessível ao entendimento simultâneo de operadores tão diversos como juristas ou magistrados, médicos e demais especialistas das áreas médicas e biomédicas, bem como a estudantes e estudiosos de nível pré e pós-graduado desta área em que todos confluem com o objetivo último de, em primeira instância, servir a justiça e, em ultima instância, servir o bem e a causa pública.

\section{BIBLIOGRAFIA}

Alonso, A., Martín, P., Albarrán, C., et al. (2005) Challenges of DNA profiling in mass disaster investigations. Croatian Medical Journal, 46, 540-548.

Amorim, A., Afonso-Costa, H., Espinheira, R. et al. (2011) Human identification with combined anthropologic and genetic tools: two case reports in forensic medicine practice. Folia Societatis Medicinae Legalis Slovacae, (1), 11-14.

Amorim, A., Vieira-Silva, C., Afonso-Costa, H. et al. (2011). Allele frequencies of all CODIS and four non-CODIS STR loci in an immigrant Brazilian population living in Lisbon preliminary results. Forensic Science International Genetics Supl, 3, e127-e128. [doi:10.1016/j.fsigss.2011.08.063]

Anđelinović, S., Sutlović, D., Ivkošić, I., et al. (2005). Twelveyear experience in identification of skeletal remains from mass graves. Croatian Medical Journal, 46, 530-539.

Budowle, B., Bieber, F., Eisenberg, A. (2005). Forensic Aspects of Mass Disasters: Strategic Considerations for DNABased Human Identification. Legal Medicine, 7(4), 230243.

Butler, J. M. (2011). Advanced Topics in Forensic DNA Typing: Methodology. Academic Press. Elsevier. London.

Butler, J.M. (2005). Forensic DNA typing. Biology, technology and genetics of STR markers ( $2^{\circ} \mathrm{ed}$ ). Academic Press. Elsevier. London.

Coble, M. (2011). The identification of the Romanovs: Can we (finally) put the controversies to rest? Investigative Genetics, 2, 20. [doi:10.1186/2041-2223-2-20]

Corte-Real, F. (2004). Forensic DNA databases. Forensic Science International, S143-S144. 
Crespillo, M., Bañón, R., Valverde, J. (2011). Aprendizaje y reflexiones de la identificación de cadáveres mediante marcadores genéticos monoparentales. Revista Española de Medicina Legal, 37(1), 17-21.

Davoren, J., Vanek D., Konjhodzić, R. et al. (2007). Highly Effective DNA Extraction Method for Nuclear Short Tandem Repeat Testing of Skeletal Remains from Mass Graves. Croatian Medical Journal, 48, 478-485.

Gojanović, M.D. \& Sutlović, D. (2007). Skeletal Remains from World War II Mass Grave: from Discovery to Identification. Croatian Medical Journal, 48, 520-527.

Ge, J., Budowle, B., Chakraborty, R. (2011). Choosing relatives for DNA identification of missing persons. Journal of Forensic Sciences, 56, S23-S28.

Graham, E. (2007) DNA Reviews: Ancient DNA. Forensic Science Medicine and Pathology, 3, 221-225.

Holland, M.M., Fisher, D.L., Mitchell, L.G. et al. (1993). Mitochondrial DNA Sequence Analysis of Human Skeletal Remains: Identification of Remains from the Vietnam War. Journal of Forensic Sciences, 38(3), 542-553.

Huffine, E., Crews, J., Kennedy, B., et al. (2001). Mass Identification of Persons Missing from the Break-Up of the Former Yugoslavia: Structure, Function, and Role of the International Commission on Missing Persons. Croatian Medical Journal, 42(3), 271-275.

Lessing, R., Rothschild, M. (2011). International standards in cases of mass disaster victim identification (DVI). Forensic Science Medicine and Pathology. [doi:10.1007/s12024011-9272-3]

Lleonart, R., Riego, E., · Saínz de la Peña, M.V. et al. (2000). Forensic identification of skeletal remains from members of Ernesto Che Guevara's guerrillas in Bolivia based on DNA typing. International Journal of Legal Medicine, $113,98-101$

Marjanović, D., Durmić-Pašić A., Bakal, N. et al. (2007) DNA Identification of Skeletal Remains from the World War Il Mass Graves Uncovered in Slovenia. Croatian Medical Journal, 48, 464-470.

Marjanović, D., Durmić-Pašić, A., Kovačević, L., et al. (2009) Identification of Skeletal Remains of Communist Armed Forces Victims during and after World War II: Combined Y-Chromosome Short Tandem Repeat (STR) and MiniSTR Approach. Croatian Medical Journal, 50, 296-304.
Milós, A., Selmanovic, A. Smajlovic, L., et al. (2007) Success rates of nuclear STR typing from different skeletal elements. Croatian Medical Journal, 48, 486-493.

Mundorff, A., Bartelink E., Mar-Cash, E. (2009). DNA Preservation in Skeletal Elements from the World Trade Center Disaster: Recommendations for Mass Fatality. Journal of Forensic Sciences, 54(4). [doi:10.1111/j.15564029.2009.01045.x]

Palo, J., Hedman, M.,Söderholm N.,Sajantila, A. (2007) Repatriation and Identification of Finnish World War II Soldiers. Croatian Medical Journal, 48, 528-535.

Pinheiro, M.F. (2009). CSI Catástrofes. Edições Universidade Fernando Pessoa. Porto.

Prinz, M., Carracedo, A., Mayr, W.R. et al. (2007) DNA Commission of the International Society for Forensic Genetics (ISFG): recommendations regarding the role of forensic genetics for disaster victim identification (DVI). Forensic Science International, 1(1), 3-12.

Rios, L., Casado, J., Prieto, J. (2010) Identification process in mass graves from the Spanish Civil War I. Forensic Science International, 199, e27-e36.

Schwark, T., Heinrich, A., Wurmb-Schawck, N. (2011) Genetic identification of highly putrified bodies using DNA from soft tissues. International Journal of Legal Medicine, 125:891-894

Vieira, D.N. (2011). Forensic Medicine - From Old Problems to New Challenges, InTech. Croatia. ISBN 978-953-307262-3.

Walsh, P.S., Metzger, D.A., Higuchi, R. (1991) Chelex 100 as a medium for simple extraction of DNA for PCR-based typing from forensic material. Biotechniques, 10(4), 506-513.

Westen, A., Gerretsen, R., Maat, G. (2008) Femur, rib, and tooth sample collection for DNA analysis in disaster victim identification (DVI). A method to minimize contamination risk. Forensic Science Medicine and Pathology, 4, 15-21. [doi:10.1007/s12024-007-0027-0]

Ziętkiewicz, E., Witt, M., Daca, P. (2011) Current genetic methodologies in the identification of disaster victims and in forensic analysis. Human Genetics, 3(1):41-60. [doi:10.1007/s13353-011-0068-7] 